\title{
Does the Real Business Cycle Help Forecast the Financial Cycle?
}

\author{
Fredj Jawadi $^{1}$ (D) Hachmi Ben Ameur ${ }^{2} \cdot$ Stephanie Bigou ${ }^{3} \cdot$ Alexis Flageollet $^{3}$
}

Accepted: 30 August 2021 / Published online: 23 September 2021

(c) The Author(s), under exclusive licence to Springer Science+Business Media, LLC, part of Springer Nature 2021

\begin{abstract}
This study investigates the relationship between the financial market and the real business cycle in the US from February 1987 to March 2016. Using different monthly time-series as proxies for the financial and macroeconomic cycles, we first specify the determinants and then build two indicators to measure the financial and real business cycles based on principal component analysis. We identify not only the main different cycles for each indicator but also measure the duration of the phases for each indicator. Second, we study the relationship between economic and financial indicators per cycle and per phase using a vector autoregressive model. Our findings show that the economic indicator is useful to forecast the financial, and that there exists a significant relationship between the financial and economic cycles that is actively stronger during the "expansion-growth" phase. This result enables investors and policymakers to better forecast the future dynamics of financial sector using the information provided by the analysis of the real business cycle.
\end{abstract}

Keywords Financial cycle $\cdot$ Real business cycle $\cdot$ PCA $\cdot$ Connectedness $\cdot$ VAR

JEL Classification B41 · C20 · G17

\section{Introduction}

The forecasting of the dynamics of the financial market as a whole and asset prices in particular has always been at the center of the debate between eminent economists.

Stephanie Bigou: The views expressed are those of the authors and do not reflect the position of Seeyond.

$\bowtie \quad$ Fredj Jawadi

Fredj.jawadi@univ-lille.fr

1 Univ. Lille, ULR 4999 - LUMEN, 59000 Lille, France

2 INSEEC School of Business and Economics, Paris, France

3 Seeyond, Paris, France 
Indeed, Eugène Fama, who is considered the father of modern financial theory, refers to his theory of market efficiency by suggesting the impossibility to forecast asset prices in the short-term. However, Robert Shiller, who shares the 2013 Nobel Prize in Economics with Eugène Fama, shows it is possible to predict asset prices in the long run. Accordingly, forecasting the dynamics of the financial sector has always been a challenge. ${ }^{1}$ That is, in line with Shiller, significant attention has been paid to the analysis of the business cycle, as well as the financial environment. This is particularly relevant as the recent global financial crisis, induced by the US subprime crisis of 2007, has led to an economic downturn for most developing, developed, and emerging countries during 2008-2009. The interaction between the US real sector ${ }^{2}$ and the financial sector has also shown further evidence of significant connectedness in the context of the ongoing Covid-19 crisis.

In the literature, numerous studies have investigated the impact of the financial sector on the business cycle (Cover \& Mallick, 2012; Rafiq \& Mallick, 2008; because the financial sector has always been considered as an important factor of production and a key economic growth driver. For example, Aikman et al. (2010) and Schularick and Taylor (2012) investigated the effect of credit on the real economy and Hatzius et al. (2010) and Benetrix and Lane (2011) measured the effect of the financial sector on the real business cycle. More recently, Drehmann et al. (2012) and Borio (2014) found further evidence of a significant relationship between the financial cycle and the macroeconomy, while Niemira and Klein (1994) developed channels to document the usefulness of financial (respectively economic) information to forecast the dynamics of the economic (respectively financial) cycle and to explain its fluctuations. Claessens et al. (2012) explained how financial and economic cycles interact, and showed strong linkages between these two cycles for 44 countries over January 1960-April 2010. In particular, they found that recessions relating to financial issues such as equity prices raids are longer and deeper than other recessions. Nevertheless, the recovery after asset price busts is weaker, whereas recoveries related to rapid growth in credit are stronger. Accordingly, the authors confirmed the effect of financial market development on the real economy. Moreover, Drehmann et al. (2012) empirically characterized the financial cycle while analyzing turning points and using frequency-based filters. They identified the financial cycle using the medium-term approach, and found that financial cycle peaks are close to financial crises, and the length of the financial cycle has augmented since 1985. Accordingly, they concluded that financial cycles are longer than economic business cycles. Further, the recessions of the business cycle are more profound when associated with the contraction phase of the financial cycle. Recently, Schüler et al. (2015) applied a multivariate spectral approach to characterize financial cycles, and identified common cycle frequencies across a set of indicators. Focusing on 13 European Union countries over 1970-2013, they showed that credit and asset prices share cyclical similarities. They also proved that the financial cycles appear long in upswing phases, with an important dispersion across countries. Interestingly, the concordance between financial and economic cycles appears only $2 / 3$ of the time,

\footnotetext{
1 See Barnett and Serletis (2000) for a concise survey.

2 For more details on the stylized facts of the US sector, see Serletis and Krause (2006).
} 
whereas that for financial cycles is apparent across countries suggesting further evidence of high heterogeneity.

Otherwise, the analyses of the usefulness of the information provided by the business cycle to forecast the financial sector are rather scarce. However, the exploration of this relationship is relevant because an investor can focus on economic conjectures before deciding to invest. Therefore, the causality from the economic conjectures to the financial sector might be different.

On the one hand, at least two main macroeconomic variables (oil price and the US dollar exchange rate) have experienced important changes and volatilities over the last decade, which have impacted the level and the duration of the phase of the business cycle. These changes have affected the cost and level of production and thus, company behavior, as companies balance investment to deal with this new economic conjuncture. Accordingly, the unemployment rate and poverty have increased, resulting in a negative shock to consumer behavior and an increase in the saving rate per measure of precaution. On the other hand, most central banks (e.g., Fed, ECB, Bank of England) have switched to new central banking rules dominated by unconventional monetary policy (e.g., quantitative easing, qualitative easing, lender of last resort, purchase of public debt, important increase of the size of the balance sheet of central banks). This switch from conventional to unconventional monetary policy is due to the zero lower band effect, which occurs when the short-term nominal interest rate is near zero. At this interest rate level, there exists a liquidity trap and the central bank is less able to stimulate economic growth. These new central banking rules also implied massive injections of liquidity into the market and are expected to impact the financial sector as well. As such, all things being equal, these factors have directly or indirectly affected financial resource allocations and thus financial cycle fluctuations. This yielded a priori close time-varying correlations between the economic and financial cycles, giving credit to Minsky's theories of cycles and the movement of the financial system from stability to fragility followed by crisis regarding the evolution of macro-economic indicators and credit conditions. ${ }^{3}$

To fill this research gap, our study proposes to check whether economic indicators can help forecast the dynamics of the financial sector. Particularly, we propose to investigate the relationship between the financial and business economic cycles as a whole and also across different phases of these cycles. To this end, we estimate the financial turning points through an analysis of turning times and fluctuations of the economic cycle. In other words, we identify the drivers of the volatility of the economic cycles and test how far they impact the fluctuations of the financial cycle.

Accordingly, our study contributes to the literature in different ways as follows. First, rather than using proxies for the economic and financial cycles as in previous studies, we carry out data analysis using an exhaustive list of macroeconomic and financial variables to specify the weighted factors through principal component analysis (PCA) to measure economic and financial cycles. Second, we apply the BBQ approach proposed by Bry and Boschan (1971) to identify the cyclical peaks and troughs for both the economic and financial indexes. Third, we identify for each index the number of cycles and distinguish the different phases of each cycle. Finally, we

\footnotetext{
3 See Prychitko (2009) for more details on this theory.
} 
investigate the connectedness between the financial and economic cycles while estimating their bilateral dependency per phase. Our findings show evidence of significant connectedness between the economic and financial cycles, with an intensity of dependency that is time-varying regarding the phase of the cycle. This is in line with the findings of Barnett et al. (2015).

The remainder of this paper is organized as follows. Section 2 presents the data and Principal Component Analysis PCA methodology. Section 3 presents the BBQ approach to computing cycles and identifying their turning points. Section 4 proposes a parametric modeling using Vector Autoregressive Model of the connectedness between the financial and real business cycles. Section 5 concludes the paper.

\section{Aggregated Economic and Financial Indicators}

\subsection{Data}

First, we identify the most representative proxies of the financial and economic sectors and capture the dynamics of their cycles using several macroeconomic and financial variables. To this end, we use monthly data from the Bloomberg databases from February 1987 to March 2016. These data includes a list of the most important financial and macroeconomic variables used in previous studies. First, regarding the financial cycle, we retained the following six financial variables:

2Y-10Y: yield spreads refer to the difference between the yields of two fixed income securities. Rising spreads lead to a positive yield curve, indicating stable economic conditions in the future. Contracting or falling spreads, on the other hand, may indicate a worsening of economic conditions in the future, resulting in a flattening yield curve.

Federal Funds Target Rate: this variable measures the Federal Funds Target Rate upper bound in the US. The federal funds rate is an indicator of the US financial market state, as it determines the interest rates charged between banks and, therefore, impacts the intervention's volume of banks on the financial markets.

Atlanta Fed Wu Xia Shadow Federal: this variable estimates of the shadow federal funds rate provided by $\mathrm{Wu}$ and Xia.

$S \& P 500$ Index: is the US stock market index based on the market capitalizations of 500 large companies having common stocks listed on the NYSE or NASDAQ.

SP500 PE Trailing: denotes the price to earnings ratio trailing 12 months. It is estimated from latest reported earnings and current market price.

HY US: defines the difference between rates on low grade and high grade bonds.

Regarding macroeconomics, we consider the following 13 variables:

Margin: provides a comprehensive measure of a company's profitability on a historical basis.

ISM Manufacturing PMI SA: is based on surveys of more than 300 manufacturing firms by the Institute of Supply Management. The ISM Manufacturing Index monitors employment, production, inventories, new orders, and supplier deliveries. 
US Industrial Production SA: measures the output of businesses integrated in industrial sector of the economy, such as manufacturing, mining, and utilities.

US CPI Urban Consumers Less Fo: is an aggregate of prices paid by urban consumers for a typical basket of goods, excluding food and energy.

US CPI Urban Consumers SA: is a measure that examines the changes in the price of a basket of goods and services purchased by urban consumers.

US PPI Finished Goods SA: is an indicator of the change of prices received by producers for their products, in particular for finished goods that are commodities that will not undergo further processing and are ready for sale to the final-demand user, as either an individual consumer or business firm.

US Unit Labor Costs Nonfarm Bu: refers to the relationship between compensation per hour and labor productivity or real output per hour, and can be used as an indicator of inflationary pressure on producers.

US Employees on Nonfarm Payroll: is reported by the US Bureau of Labor Statistics. It represents the total number of paid U.S. workers of any business. Despite the name nonfarm payroll, the report excludes workers from general government jobs, private household jobs, employees of nonprofit organizations, and farm employees.

US Initial Jobless Claims SA: measures the number of individuals who filed for unemployment insurance for the first time during the past week.

Unemployment Rate: is obtained from the sources of the US Bureau of Labor Statistics and proxies the unemployment level in the US.

US Durable Goods New Orders: a government report that measures consumer spending on long-term purchases, that is, products that are expected to last more than three years.

Taylor Rule Estimate: a forecasting model used to determine the central bank interest rate.

Earnings Reported: economic indicators allow analysis of economic performance and predictions of future performance.

The selection of this data is justified by its ability to capture the main key features of the economic and financial cycles and reproduce their dynamics either in the short or long term. That is, in practice, for data homogeneity, we integrated the data and used only stationary time-series. Further, we transformed the data so that only centered and reduced time-series are employed.

\subsection{Measure of Aggregated Financial and Economic Indicators Using PCA}

PCA computes the principal components from correlated variables based on their orthogonal transformation to convert them to uncorrelated linear variables. By definition, this transformation attributes to the first principal component the largest possible variance to account for significant variability in the data. This statistical approach, introduced by Pearson (1901) and developed hereafter by Hotelling (1933, 1936), is used to explore data and specify predictive models, producing component scores that are also called factor scores.

In our analysis, we use PCA to identify the factor scores for the financial and economic cycles. Accordingly, we generate financial and economic indicators according to 


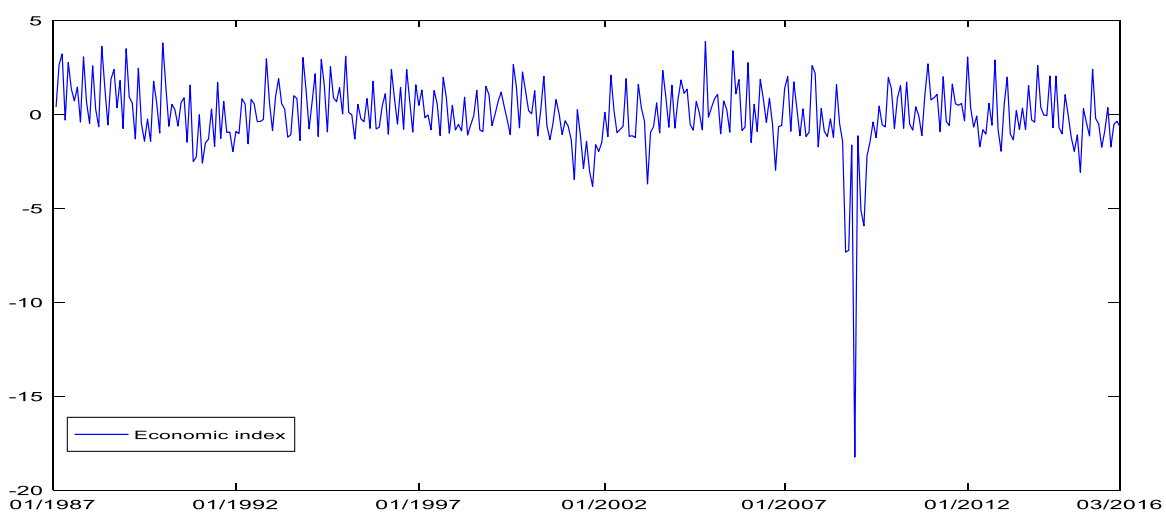

Fig. 1 Economic index based on a single PCA factor

two options: i) taking only the first factor identified by the PCA each time, and ii) taking an aggregation of the first important factors in the PCA. Figure 1 presents the dynamics for extracting one factor from the economic variables, which is used as a proxy of the economic index. Accordingly, although the first factor explains $25.9 \%$ of the data variation, the retained component captures different returning points and fluctuations characterizing the data, in particular, for the economic downturn of 2008-2009.

However, when dealing with more than one factor, as shown in Figs. 2 and 3, five factors explain $70.39 \%$ of the total data variability and provide a clearer presentation of real business cycle fluctuations.

Figure 4 presents the dynamics of the economic index based on five factors. We observe a similarity with the pattern based on one factor in Fig. 1. The main difference consists in more volatility due to including more components.

As for the economic index, Fig. 5 presents the dynamics of the financial index based on one factor. The first component captures $36.42 \%$ of the total variation of the financial variables. This component shows several episodes of high volatility, as well as the turning points of the financial index.

We extend this data analysis to check whether other factors improve the representation of the financial index. Our results, reported in Figs. 6 and 7, identify four factors that explain $80.98 \%$ of the total data variance.

Finally, we compute and plot in Fig. 8 the dynamics of the financial index using the main four factors, which helps us to capture more volatility in the data.

\subsection{Preliminary Connectedness Tests}

To provide an overview of the relationship between the financial and real business cycles, we carry out preliminary tests and report hereafter the main findings. First, Figs. 9 and 10 report the dynamics of the financial and economic indexes when being proxied by a single PCA factor and multiple factors, respectively. Accordingly, strong linkages exist between the two indexes under consideration, and both the financial and real business cycles appear to be inter-linked. Further, while this relationship is 
Scree Plot (Ordered Eigenvalues)

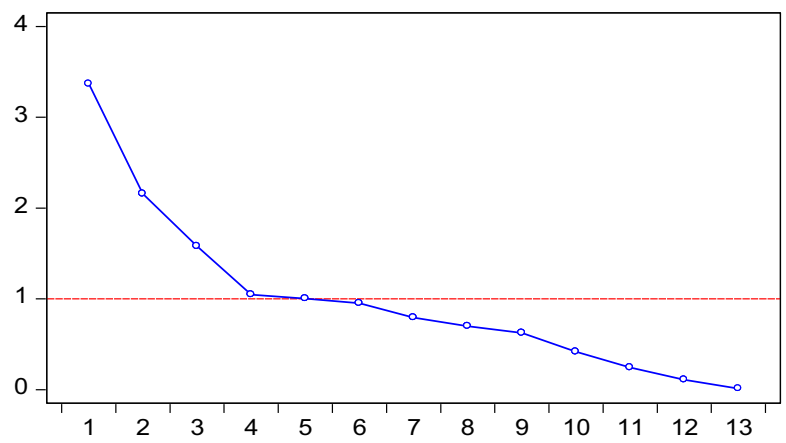

Eigenvalue Cumulative Proportion

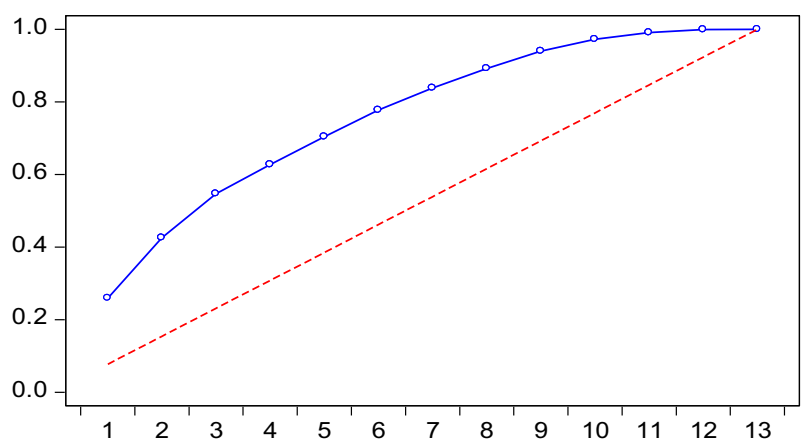

Fig. 2 Identification of PCA factors for the economic index

Fig. 3 Measure of PCA factor contribution to the economic index

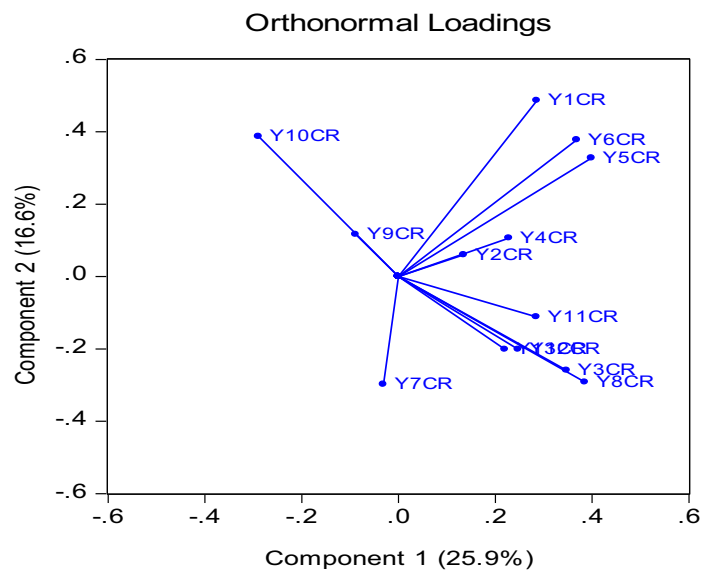




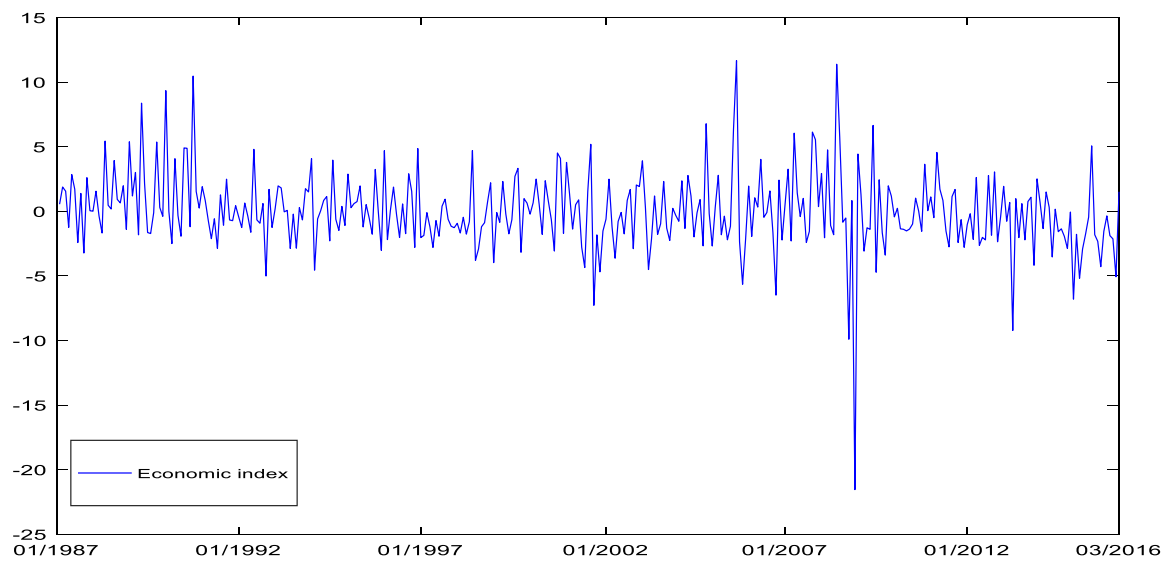

Fig. 4 Economic index based on five PCA factors

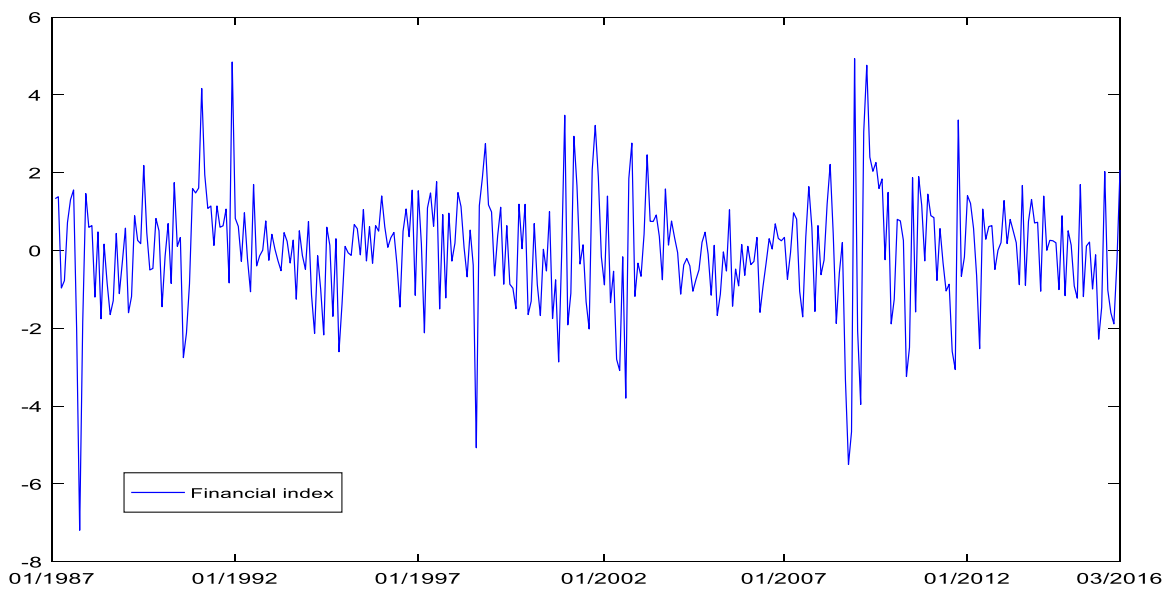

Fig. 5 Financial index based on one PCA factor

significant at the end of the period, it is worth noting that the lead-lag effects between the two indexes appear alternatively and vary with the period and phase of the cycle.

Further, as previously mentioned, when considering more PCA factor scores (Fig. 10), we confirm the previous analysis results even if we capture more volatility in both indices. This suggests that the information from the economic index might be helpful to better predict the dynamics of the financial cycle and vice versa, which is in line with the literature.

Next, we also compute the descriptive statistics of the financial and economic indexes to better understand their properties. Accordingly, we note that, on average, both indexes show near-zero values, suggesting further evidence of strong correction. The maximum value for the financial indicator (4.9341) corresponds to December 2008, while the minimum value (-7.1918) corresponds to October 2008, reflecting 
Scree Plot (Ordered Eigenvalues)

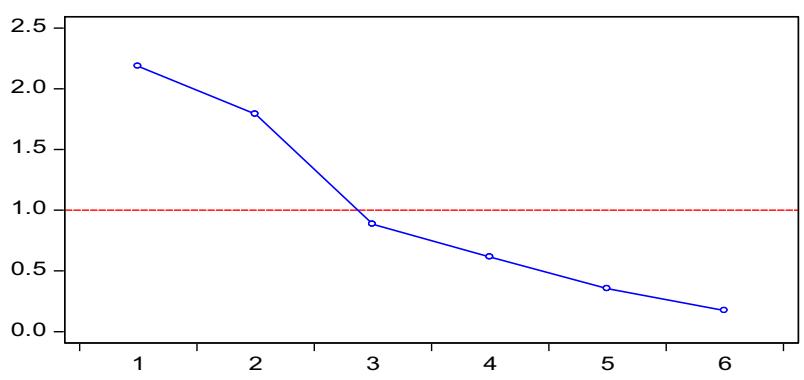

Eigenvalue Cumulative Proportion

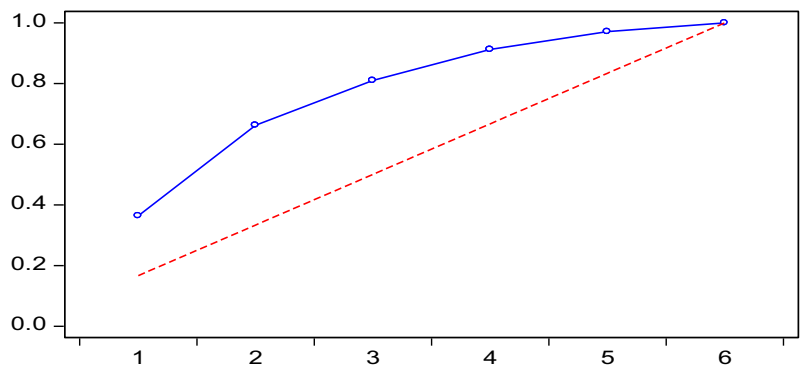

Fig. 6 Identification of PCA factors for the financial index

Fig. 7 Measure of PCA factor contribution to the financial index

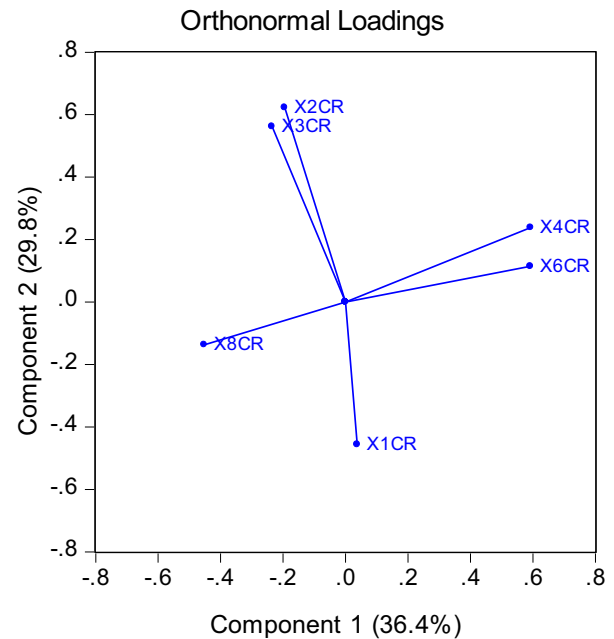




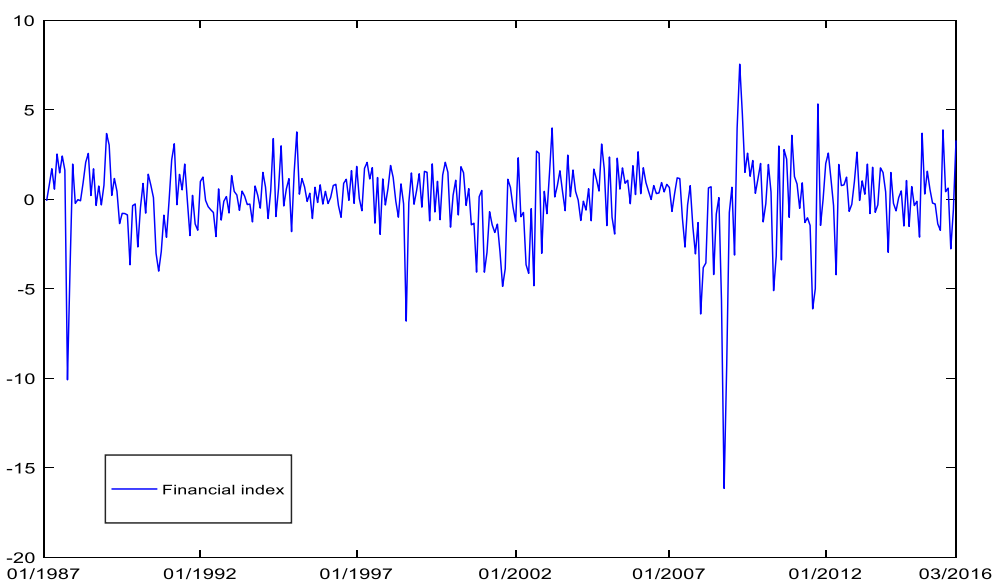

Fig. 8 Financial index based on four PCA factors

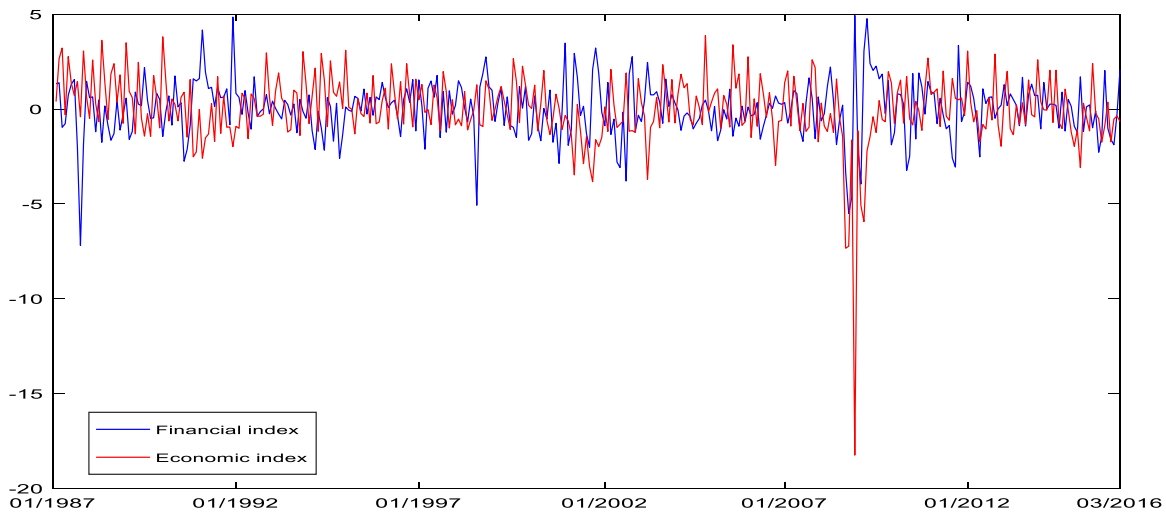

Fig. 9 Dynamics of financial and economic indices obtained based on one factor

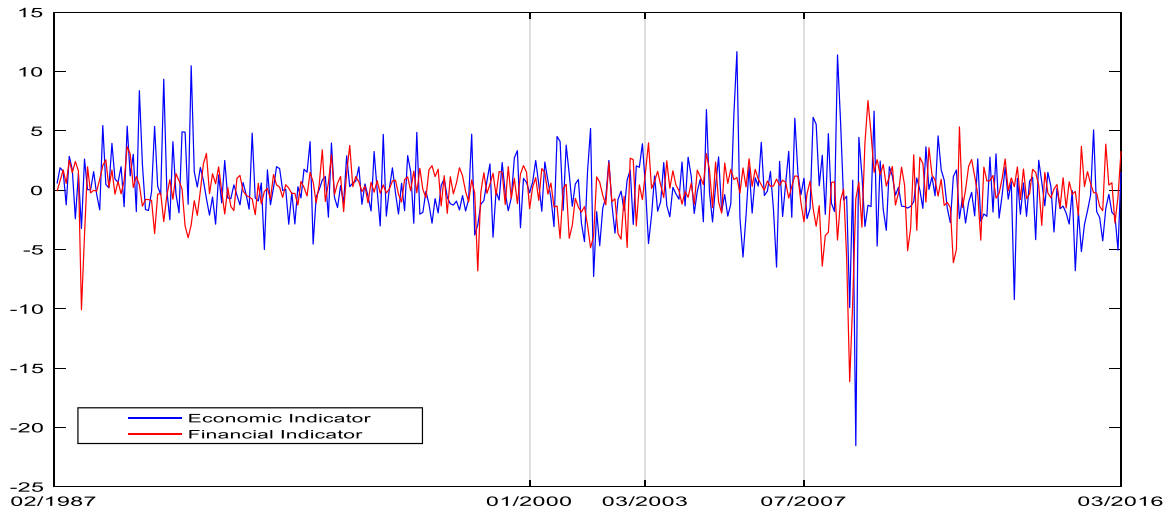

Fig. 10 Dynamics of financial and economic indices obtained based on five factors 
Table 1 Descriptive statistics

\begin{tabular}{lll}
\hline & Economic index & Financial index \\
\hline Mean & $-5.7143 \mathrm{e}-09$ & $-.4286 \mathrm{e}-08$ \\
Median & -0.0681 & 0.1328 \\
Maximum & 3.8727 & 4.9341 \\
Minimum & -18.2430 & -7.1918 \\
Standard deviation & 1.8350 & 1.4781 \\
Skewness & -3.1060 & -0.4284 \\
Kurtosis & 30.9894 & 5.7105 \\
Jarque-Bera & $1.1987 \mathrm{e}+04$ & 117.8476 \\
\hline
\end{tabular}

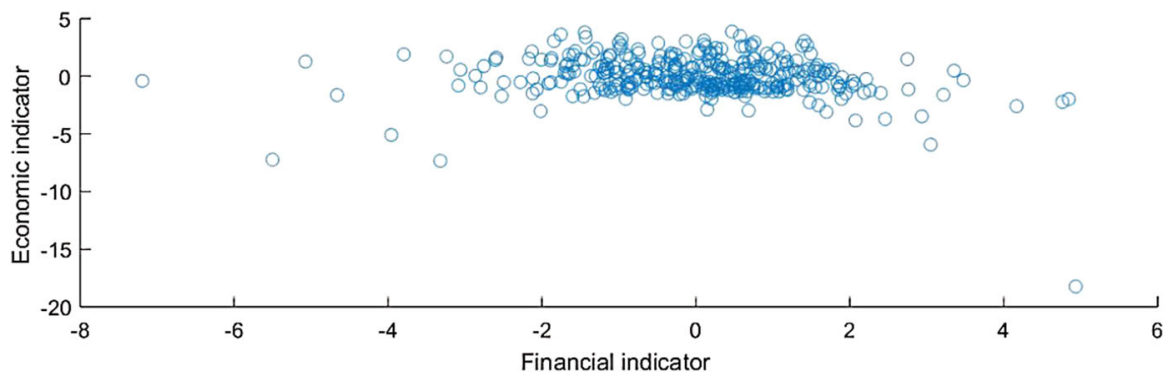

Fig. 11 Scatter dynamic between the financial and economic indexes

the important volatility of financial data around the global financial crisis. As for the economic indicator, minimum and maximum values correspond to the values of December 2008 and November 2004, respectively. That is, the economic index appears to be more volatile than the financial index, while both indexes show evidence of asymmetry, leptokurtic excess, and non-normality (Table 1).

In the next step, we analyze the relationship between the economic and financial cycle indicators. To this end, we first compute the scatter dynamics and report it in Fig. 11. Accordingly, the scatter is characterized by an important dispersion excess, suggesting the relationship between these two indicators exhibits asymmetry and/or time-variation. The time-varying relationship between these two indicators suggests this relationship does vary with the phase of the business cycle.

Hereafter, we compute the unconditional correlations between the financial and real business indexes for different sub-periods ${ }^{4}$ and report the main results in Table 2. From Table 2, as the time-varying connectedness between the real business and financial cycles is not rejected, we note that this relationship is always negative, thus implying a negative reaction of the financial cycle after a shock to the economic cycle. Further,

\footnotetext{
${ }^{4}$ The sub-periods are defined based on the periods of the different crises (2000 for the dot-com bubble crisis. 2003 for the US housing bubble, 2007 for the subprime crisis; and 2010 is related to European sovereign debt).
} 
Table 2 Unconditional correlation matrix

\begin{tabular}{ll}
\hline Sub-sample & Unconditional correlation \\
\hline $02 / 1987-03 / 2016$ & -0.1801 \\
$02 / 1987-1 / 2000$ & -0.2869 \\
$2 / 2000-3 / 2003$ & -0.3508 \\
$4 / 2003-07 / 2007$ & -0.3398 \\
$08 / 2007-03 / 2016$ & -0.0706 \\
\hline
\end{tabular}

while this relationship attains high values between 2003 and 2007, the relationship between the two indexes shows a weak level after August 2007.

Overall, while these findings do not reject the hypothesis of time-variance between the financial and real business cycles, we cannot concisely identify the contribution of the economic (respectively financial) cycle to explain the dynamics of the financial (respectively economic) cycle. To this end, we propose hereafter to identify the different cycles, specify their turning points, and analyze this relationship for each phase of the cycle.

\section{Identification of Cycle Phases}

In the literature, the main analyses to identify business cycle dating consist of the identification of the troughs and peaks of the economic activity, that is, the so-called turning points, which separate the phases of a business cycle. In our analysis, we first identify the financial and economic cycles dating based on the turning-point analysis applied to financial and economic indices based on PCA. Second, we identify the economic and financial cycles based on the exponential filter. Turning-point analysis, originally proposed by Bry and Boschan (1971), aims to computerize the algorithm for monthly series. In this study, we use the MBBQ ${ }^{5}$ MATLAB program by James Engel, which is more computationally efficient than the original Bry-Boschan (BB) and BB quarterly algorithms.

Further, the MBBQ program can be applied to monthly and yearly data. Basically, the BBQ algorithm preserves the classical cycles methodology's focus on duration and turning points. The essence of this methodology is identifying turning points and separating periods of relative expansion from contraction in aggregate economic activity. In particular, the determination of a peak and a trough at period $t$ is based on the following rules:

$$
\left\{\begin{array}{l}
\text { Peak: } \Delta_{2} y_{t}>0 \cap \Delta y_{t}>0 \cap \Delta y_{t+1}<0 \cap \Delta_{2} y_{t+2}<0 \\
\text { Through: } \Delta_{2} y_{t}<0 \cap \Delta y_{t}<0 \cap \Delta y_{t+1}>0 \cap \Delta_{2} y_{t+2}>0
\end{array}\right.
$$

where $\Delta_{2} y_{t}=y_{t}-y_{t-2}$ and $\Delta y_{t}=y_{t}-y_{t-1} ; y_{t}$ is the studied series (financial or economic indices).

\footnotetext{
5 MBBQ uses the modified Bry-Boschan (BB) program without any smoothing techniques.
} 
Table 3 Turning-point analysis economic and financial indices

\begin{tabular}{lrl}
\hline Sub-periods & \multicolumn{1}{c}{ Troughs } & \multicolumn{1}{l}{ Peaks } \\
\hline \multicolumn{2}{l}{ Turning-point analysis economic index } \\
1 & $04 / 30 / 1991$ & \\
2 & $02 / 27 / 1998$ & $05 / 31 / 1994$ \\
3 & $09 / 28 / 2001$ & $08 / 31 / 1999$ \\
4 & $12 / 31 / 2008$ & $02 / 28 / 2005$ \\
Turning-point analysis financial index & $03 / 31 / 2011$ \\
1 & $04 / 29 / 1988$ & \\
2 & $05 / 31 / 1994$ & $07 / 31 / 1991$ \\
3 & $05 / 31 / 2000$ & $11 / 29 / 1996$ \\
4 & $05 / 31 / 2005$ & $09 / 28 / 2001$ \\
5 & $07 / 29 / 2011$ & $04 / 30 / 2007$ \\
\hline
\end{tabular}

When applying the MBBQ approach to the economic and financial indices, we obtain the results reported in Table 3 .

Table 3 shows four and five cycles for the economic and financial indices, respectively. Interestingly, our findings capture and reproduce the major downturns and crises that have characterized the economic and financial cycles during this period (the URSS event in 1991, the Internet bubble in 2000, the US subprime crisis in 2007, the recent global financial crisis in 2008, the public debt crisis in 2010-2011, etc.), suggesting our financial and economic indicators computed by PCA are appropriate proxies for the financial and economic cycles.

Once the turning points are identified, the sample period can be partitioned into sub-periods or phases of expansions (between troughs and peaks) and contractions (between peaks and troughs) that can be identified using an exponential filter. Next, we use the exponential filter to specify the economic and financial cycles. The exponential filter is an empirical method of smoothing and forecasting. The data are smoothed successively starting from the initial value and using some weighted past observations. ${ }^{6}$ The exponential filter is one of the windowing methods used in signal processing, which turns as a low-pass filter by removing high frequencies from the initial signal.

In this study, we consider the exponential filter for the estimation of the tendency of the financial and economic indexes. Formally, the exponential filter procedure considers each observation as:

$$
X_{t}=b+\epsilon_{t}
$$

where $b$ is a constant and $\epsilon_{t}$ is the error term.

Constant $b$ implies the stability of the series but might change slowly over time. The exponential filter allows determining the systematic part of the series $\left(X_{t}\right)$ by computing, for example, the moving average where the current and immediately preceding

\footnotetext{
6 The weight of past observation decreases exponentially over time.
} 
observations are assigned greater weights than the respective older observations. In this procedure, past observations exponentially decreases their weight over time.

The formula for a simple exponential smoothing $\left(S_{t}\right)$ can be re-written as:

$$
S_{t}=\alpha X_{t}+(1-\alpha) S_{t-1}
$$

where $\alpha$ is the ponderation parameter and $S_{0}=X_{0}$.

The main results for economic and financial cycles are plotted in Figs. 12 and 13, respectively.

Overall, our findings confirm the cycles for economic and financial indexes that appear to interact differently, suggesting connectedness between the financial sector and real business cycle.

In the last step, we check this relationship between economic and financial cycles and specify the lead-lag relationship.

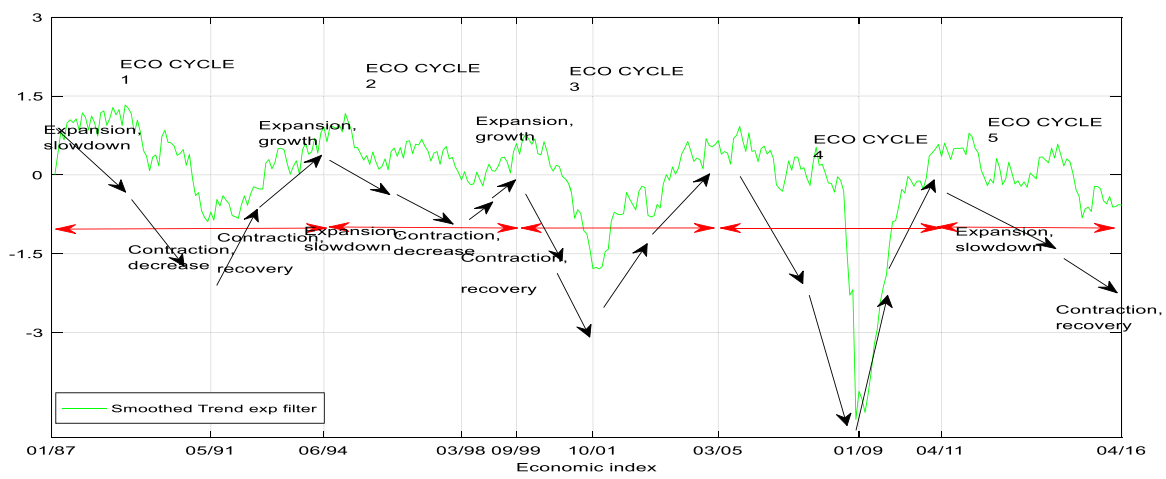

Fig. 12 Phases and turning points of the economic index

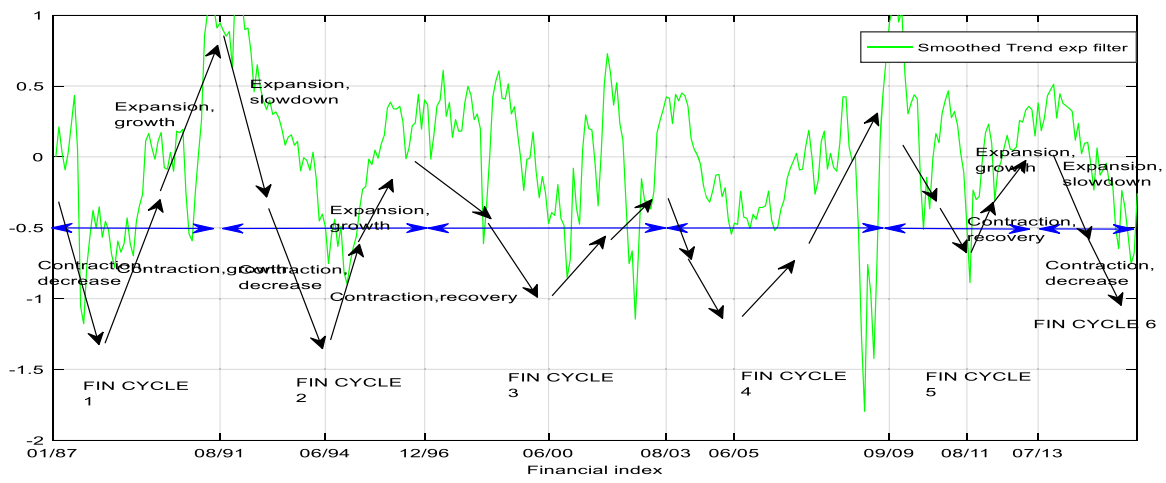

Fig. 13 Phases and turning points of the financial index 


\section{Modeling Causality and the Lead-Lag Relationship Between Financial and Economic Indexes}

We analyze the causality between the economic and financial indexes through a VAR model that allows an analysis of the relationship and establishes further linear causality between the financial and the macroeconomic indexes. In particular, our previous analysis investigated the relationship between the financial and economic cycle indexes. However, based on our finding of the phases and turning points identification of financial and economic indexes, the relationship might be lead-lag. This intuition is motivated by previous studies. To check this hypothesis, we specify a bivariate VAR model, which allows analyzing the dynamics of each index based on its lags and the lags of the other market. Further, we might employ a Granger causality test based on this VAR model including the appropriate lags and estimate the impulse response function for each market to the shock of the other market. The general form a VAR(p) is as follows:

$$
y_{t}=v+A_{1} y_{t-1}+\cdots+A_{p} y_{t-p}+u_{t}
$$

where $v$ is constant $\mathrm{K}$-vector for the intercept, and $u_{t}$ multivariate white noise process. $A_{j}$ is a matrix of regression with $\left(k^{*} k\right)$ dimensions, with $j=1, \ldots, p . y_{t}$ is the vector of dependent variable with a dimension $\left(k^{*} 1\right)$, each component of the vector this $y_{t, k}$ depends on the $\mathrm{p}$ lags of itself of the other $T-1$ component variable (with $k=1, \ldots$, $T)$. In our case, $k=2$, which corresponds to the financial and economic cycle factors. The lag criteria selection based on the Akaike and Schwarz criterion show $p=3$. The results of the Granger causality tests are presented in Table 4 and those of the VAR model in Table 5.

Table 4 points to significant evidence of bilateral causality between the economic and financial indexes at the 5\% level, suggesting the usefulness of previous information for both indexes to improve the forecasting of their future dynamics.

From Table 5, the financial economic index reacts positively and negatively for the corresponding month and third month of the economic index movement, respectively. However, the economic index responds significantly and positively for past one- and three-month changes of the financial index. This analysis confirms the delay in the reaction between the two indexes. These results are in line with those of the wavelet analysis.

Finally, we estimate the impulse response functions from our VAR (3) specification to better understand the interaction between the economic and financial cycles, which we report in Figs. 14 and 15. Figure 14 displays the reaction of the financial cycle to economic shocks. We find that, after a positive economic shock, the effect is positive

Table 4 Granger causality tests results

\begin{tabular}{lll}
\hline Dependent variable & Test statistic & P-value \\
\hline Economic index & 19.66 & 0.00 \\
Financial index & 19.29 & 0.00 \\
\hline
\end{tabular}


Table 5 VAR estimates

\begin{tabular}{lll}
\hline & $F 1 X C R_{t}$ & $F 1 Y C R_{t}$ \\
\hline$F 1 X C R_{t-1}$ & $0.198^{* * *}$ & $0.180^{* * *}$ \\
$F 1 X C R_{t-2}$ & $-0.116^{* *}$ & $0.101^{*}$ \\
$F 1 X C R_{t-3}$ & 0.034 & $0.123^{* *}$ \\
$F 1 Y C R_{t-1}$ & $0.08^{*}$ & 0.032 \\
$F 1 Y C R_{t-2}$ & 0.0002 & $0.222^{* * *}$ \\
$F 1 Y C R_{t-3}$ & $-0.196^{* * *}$ & $0.367 * * *$ \\
$\operatorname{constan}_{t}(v)$ & -0.001 & 0.016 \\
$\bar{R}^{2}$ & 0.076 & 0.240 \\
Portmanteau test & $4.418(0.347)$ &
\end{tabular}

$* * *$, and *** denote significance at the $10 \%, 5 \%$, and $1 \%$ levels, respectively. The null hypothesis of the $\mathrm{Q}$ statistic of the Portmanteau test is of no residual autocorrelations up to length $h$. (.) denotes the pvalue. F1XCR $\mathrm{t}_{\mathrm{t}}$ denotes the economic index and $\mathrm{F} 1 \mathrm{YCR}_{\mathrm{t}}$ the financial index

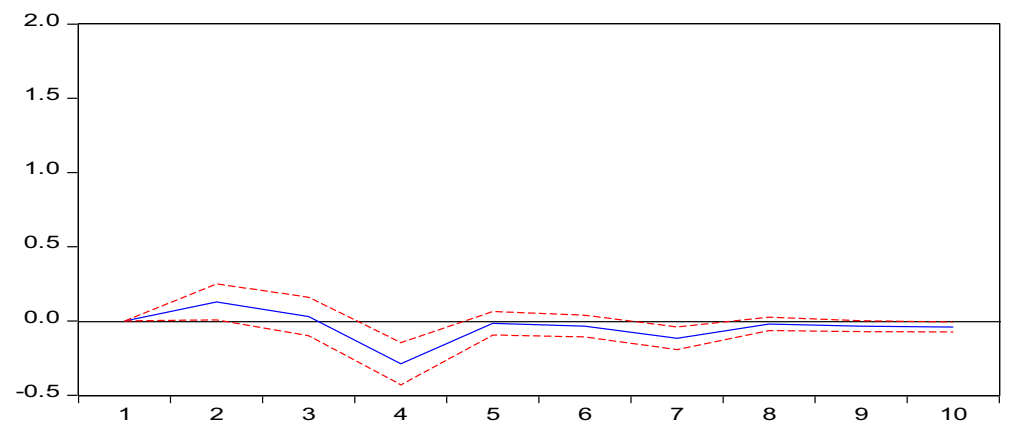

Fig. 14 Response of financial cycle to economic shocks

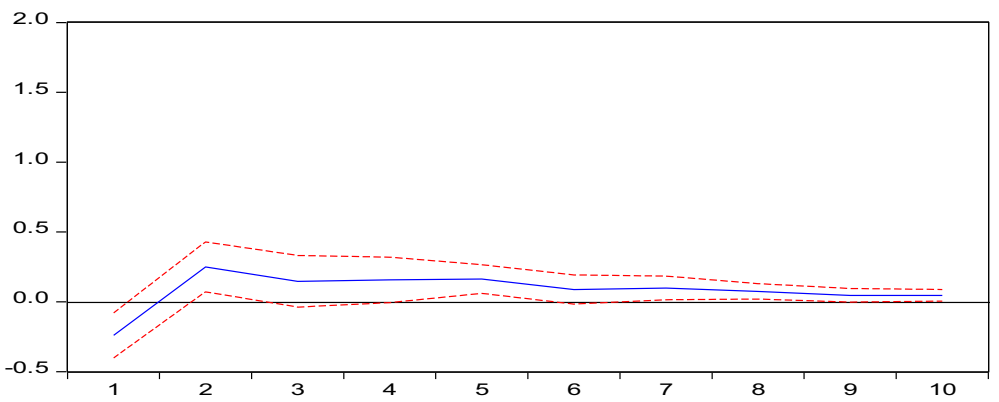

Fig. 15 The response of the financial cycle to an economic shocks 
for the financial cycle even if not immediate, but turns negative from the second month and recovery is rather slow. This result is in line with our wavelet findings, as we show a persistent effect in the long run after turmoil periods. Figure 15 displays the reaction of the economic cycle to financial shocks, which is positive but persistently decreasing and then disappearing after 10 months.

\section{Conclusion}

This study computes two measures of economic and financial indicators using a set of important macroeconomic and financial variables under PCA. Further, we investigate the assumption of connectedness between these two cycles in a linear framework (vector linear models, Granger causality tests). Our results show significant and timevarying relationships between the economic and financial cycles that are stronger during "expansion-growth" phase. This finding is particularly interesting, as it suggests the usefulness of the information provided by the economic cycle/tendency to better forecast the future dynamics of the financial cycle.

\section{References}

Aikman, D., Haldane, A., \& Nelson, B. (2010). Curbing the credit cycle. Paper presented at the Columbia University Center on Capitalism and Society annual conference, New York.

Barnett, W. A., \& Serletis, A. (2000). Martingales, nonlinearity, and chaos. Journal of Economic Dynamics and Control, 24(5-7), 703-724.

Barnett, W. A., Serletis, A., \& Serletis, D. (2015). Nonlinear and complex dynamics in economics. Macroeconomic Dynamics, 19(8), 1749-1779.

Benetrix, A., \& Lane, P. R. (2011). Financial cycles and fiscal cycles. Trinity College.

Bloomfield, D. S., McAteer, R. T. J., Lites, B. W., Judge, P. G., Mathioudakis, M., \& Keenan, F. P. (2004). Wavelet phase coherence analysis: Application to a quiet-sun magnetic element. Astrophysics Journal, $617,623-632$.

Borio, C. (2014). The financial cycle and macroeconomics: What have we learnt? Journal of Banking and Finance, 45, 182-198.

Bry, G., \& Boschan, C. (1971). Cyclical analysis of time series: Procedures and computer programs. National Bureau of Economic Research.

Claessens, S., Kose, M. A., \& Terrones, M. (2012). How do business and financial cycles interact? Journal of International Economics, 87(1), 178-190.

Cover, P., \& Mallick, S. (2012). Identifying sources of macroeconomic and exchange rate fluctuations in the UK (with James P. Cover). Journal of International Money and Finance, 31(6), 1627-1648.

Drehmann, M., Borio, C., \& Tstasaronis, K. (2012). Characterising the financial cycle: Don't lose sight of the medium term! BIS Working Papers, no. 380, Bank for International Settlements.

Goupillaud, P., Grossman, A., \& Morlet, J. (1984). Cycle-octave and related transforms in seismic signal analysis. Geoexploration, 23, 85-102.

Hatzius, J., Hooper, P., Mishkin, F., Schoenholtz, K., \& Watson, M. (2010). Financial conditions indexes: A fresh look after the financial crisis. NBER Working Papers, no. 16150.

Hotelling, H. (1933). Analysis of a complex of statistical variables into principal components. Journal of Educational Psychology, 24, 417-441.

Hotelling, H. (1936). Relations between two sets of variates. Biometrika, 28(3/4), 321-377.

Niemira, M. P., \& Klein, P. A. (1994). Forecasting financial and economic cycles. Wiley.

Pearson, K. (1901). On lines and planes of closest fit to systems of points in space. Philosophical Magazine, 2(11), 559-572. 
Prychitko, D. L. (2009). Competing explanations of the Minsky moment: The financial instability hypothesis in light of Austrian theory. The Review of Austrian Economics, 32(3), 1999.

Rafiq, M. S., \& Mallick, S. (2008). The effect of monetary policy on output in Emu3: A sign restriction approach. Journal of Macroeconomics, 30(4), 1756-1791.

Rua, A., \& Nunes, L. (2009). International comovement of stock market returns: A wavelet analysis. Journal of Empirical Finance, 16, 632-639.

Schularick, M., \& Taylor, A. (2012). Credit booms gone bust: Monetary policy, leverage cycles, and financial crises, 1870-2008. American Economic Review, 102(2), 1029-1061.

Schüler, Y., Hiebert, P., \& Peltonen, T. (2015). Characterising the financial cycle: A multivariate and time-varying approach. Working Paper Series, no. 1846, ECB, Frankfurt am Main.

Serletis, A., \& Krause, D. (2006). Nominal stylized facts of U.S. business cycles. World Scientific Book Chapters. In Money and the economy, chapter 2 (pp. 47-56). World Scientific.

Torrence, C., \& Compo, G. P. (1998). A practical guide to wavelet analysis. Bulletin of the American Meteorological Society, 79, 61-78.

Publisher's Note Springer Nature remains neutral with regard to jurisdictional claims in published maps and institutional affiliations. 